Collins, L. \& Nerlich, B. (2016) "Uncertainty discourses in the context of climate change: A corpusassisted analysis of UK national newspaper articles." Communications - the European Journal of Communication Research Special Issue "Scientific uncertainty in public discourse" 41(3): 291-313. doi: 10.1515/commun-2016-0009

\title{
Uncertainty discourses in the context of climate change: A corpus-assisted analysis of UK national newspaper articles
}

\begin{abstract}
Uncertainty is intrinsic to science, to knowledge acquisition and risk assessment. When communicating about climate change however, uncertainty can be used and understood as 'not knowing', i.e. as ignorance. In this article we aim to understand how 'uncertainty' is used in a specific cultural and media context at two important periods in time. Using a corpus linguistic approach, we examine how 'uncertainty' is used in the context of UK press coverage of climate change in 2010 (following 'Climategate') and in 2014-15, after the latest IPCC report had been published. We find that after climategate and the (failed) Copenhagen summit 'uncertainty' was used to question the authority and credibility of climate science; after the latest IPCC report and in the run-up to the (more successful) Paris summit discussions focused on uncertainties inherent in various climate change mitigation activities and associated with the economy, environment and politics more generally.
\end{abstract}

Keywords: uncertainty; climate change; climate science; UK press; corpus linguistics

\section{Introduction}

Uncertainty is all around us. As Stuart Firestein points out in a review of Helga Nowotny's (2015) book The Cunning of Uncertainty: "For scientists, uncertainty is a norm. Experiments begin with uncertainty (why else do them?), and even when they are 'successful', the results contain only a range of certainty and a range of confidence about that certainty. Yet in the world outside the laboratory, uncertainty is perceived as negative — not a data point, but a failing, effectively no better than not knowing" (Firestein, 2015, p.638). This 'dual use' of uncertainty introduces confusion into climate change communication.

A whole Uncertainty Handbook (Corner et al., 2015) tries to get to grips with this issue. In a blog post entitled "The Uncertain World: Is uncertainty used as a stick with which to beat climate 
change?" the main editor of the handbook, Adam Corner, points out: "Uncertainty runs through climate science like the lettering in a stick of rock. It will never 'go away' and no communication strategy should ever aim for this." (Corner, 2014, italics added).

We have, it seems, two metaphorical sticks: a stick of rock (or candy), symbolising climate science, which, like all science, thrives on and forever deals with uncertainty; and another stick (say, of wood) used mainly by those sceptical of that science to question its validity and delay climate change policies. A special issue of Philosophical Transactions A, devoted to 'uncertainty', tries to counteract the latter use of uncertainty and claims that uncertainty is in fact a form of knowledge rather than ignorance (Lewandowsky et al., 2016). Greater uncertainty, the authors argue, implies greater risk and this calls for greater political action rather than greater inaction.

When looking at these discussions, it is surprising to note that there seems to be a lack of indepth reflection on how the word 'uncertainty' is used 'in the real world': in ordinary language. In a recent article, Landström et al. (2015: 277) claim that: "The meanings of scientific uncertainty in society arise in cultural processes involving more than science and scientists; it is a phenomenon with different meanings depending on the context. [...] If we understand scientific uncertainty as having multiple meanings, it is interesting to look at whose definitions get communicated and used in which contexts".

Traditional media still form part of the cultural context or the 'cultural circuits' (Carvalho and Burgess, 2005) in which meanings of scientific uncertainty circulate and mingle with ordinary language meanings of uncertainty, anxiety and doubt (Nerlich, 2012). This study was carried out following the publication of the final part of the Fifth Assessment Report (AR5) in April 2014, which reflected a focus on mitigation of climate change following the IPCC's assertion that "Warming of the climate system is unequivocal" (http://www.ipcc.ch/pdf/assessmentreport/ar5/wg1/WGIAR5 SPM brochure en.pdf) - its strongest statement to date on the scientific knowledge relevant to climate change. In order to gain a better understanding of the multiple meanings of uncertainty in specific historical, cultural and media contexts, we therefore compare and contrast UK national newspaper coverage at two important points in time and ask:

- How is 'uncertainty' discussed in 2010, the year after 'Climategate', which happened at the end of 2009 ? 
- How is 'uncertainty' discussed in 2014-15, the year after the latest IPCC report was published?

- What are the implications for climate change communication?

\section{Methodological framework}

We adopt a corpus-driven approach in order to reveal differing discourses of 'uncertainty', both in relation to but also in proximity to 'climate change'. Corpus linguistics offers statistical validation to observed features of the data that can inform critical readings of the discourse and, as such, reveal embedded patterns across the data that may not be perceived by the reader/researcher. The quantitative indicators generated from corpus analysis also offer 'entry points' in order to conduct a qualitative textual analysis. As such, this study examines the broader semantic categories of the data that operate in shaping the climate change debate in relation to other sociocultural aspects such as the economy, but also in the very local description of climate change as, for example 'uncertain' or 'dangerous'.

In addition to considering those lexical and semantic features that occur directly in discussions of climate change, we also consider how uncertainty is discussed in proximity to climate change debate. For example, a text that discusses whether or not President Obama can establish an international climate change agreement would be noteworthy because the author has not characterised climate change as 'uncertain', rather the political action in response to it. Equally, by citing "Clinton administration climate change official Paul Bledsoe" the phenomenon of "climate change' is referenced 'as given' and one that warrants a political advisor. This allows us to discuss what according to Fairclough (2003) might be considered a "significant absence", taking into consideration "what is actually present and what might have been present but is not" (pp. 36-37).

As Pan and Kosicki (1993, p.59) observe: "a headline is the most salient cue to activate certain semantically related concepts in readers' minds". As part of this article we therefore also studied headlines to gain a deeper understanding of the salience of uncertainty at two periods in time. Headlines not only operate in demonstrating the 'newsworthiness' (importance) and 'aboutness' (topic) of the article (Ungerer, 2000) but set out from the very first line particular (semantic) signposts through which the content of the article underneath is to be understood (van Dijk, 1988; Scollon, 2000). In online newspaper contexts where the 'front page' is often an assortment of hyperlinks to the 
article content itself, the headline can be the determining factor in whether an article is even accessed.

Before we discuss our methods in more detail and then report and discuss our findings, it is necessary to provide a short historical background section to the two periods in the climate change debate that we study.

\section{Historical Background}

\section{0 corpus}

Debates about climate change have a long history. However, observers agree that 1988 , when the International Panel on Climate Change was created, was the year that climate change became a matter for politics (Jaspal and Nerlich, 2014). From then onwards there was, on the one hand, a steady accumulation of scientific evidence (and certainty) that climate change was happening and was caused or exacerbated by human activities and, on the other hand, a relatively steady increase in media attention to the matter, reaching a peak in 2007. Scientists, the media and policy makers (especially in Europe and the UK) began to work in an atmosphere characterised by a sense that one knew what climate change was, that it was real, and that the only thing that remained to be done was change people's behaviour. To do this, better communication strategies were called for and public engagement efforts were intensified.

In November 2009, Climategate turned the tables on science and on certainty (Nerlich, 2010; Koteyko et al., 2014). Hacked emails between climate scientists from the Climatic Research Unit at the University of East Anglia, which were released just before an important climate summit in Copenhagen in November 2009, seemed to provide evidence for the fact that climate scientists had manipulated and hidden data, suppressed critical voices and that they were engaged in conspiracy and fraud. The scientists implicated in the purported scandal were exonerated in multiple inquiries, but the dent to the credibility of climate science has lingered ever since. Uncertainty and doubt became, for a while, a dominant discussion point in climate change debates. A 2013 report by James Painter estimated that, at that time, $82 \%$ of articles in which the focus was on climate change talked about 'disaster' and 'uncertainty' (Painter, 2013). The report therefore suggested that it might be better to shift from a language of uncertainty to one of 'risk'. 
2009 and 2010 were also years of economic uncertainty, as the global financial crisis, which had started in 2008 , began to take its toll. This was also when the scientific community began to discuss the risks and benefits of geoengineering (Nerlich and Jaspal, 2012) and when the US began to see a boom in fracking or hydraulic fracturing of shale gas containing rock, a technology that was, at the time, regarded with great suspicion in the UK.

\section{4/15 corpus}

The end of 2014 saw the fifth anniversary of Climategate, which coincided with the release of the IPCC's fifth assessment synthesis report for policy makers (this report was preceded by various other reports which were published in stages from early 2013 onwards). This report became a stepping stone on the 'road to Paris', that is, the Paris climate summit at the end of 2015. This report was released at a time when the global economic crisis was easing but other global events, such as the crisis in the Ukraine, led some European countries to review their energy policies and revisit fracking.

In the UK the general election was very much in the news in early 2015 , which also meant a focus on policy issues, implicating economic and energy concerns. The end of 2015 was marked by the Paris summit. Although this is not captured within the parameters of our data set, our analysis of UK national newspapers indicates that the second period we studied contains the seeds for a markedly different discourse on uncertainty compared to the first. This difference was noted by Painter, who reported: "A very impressionistic take on coverage from Paris suggests that there are significantly more stories about renewables, new technologies, and business opportunities. Such stories are one indication of how media narratives about climate change may be becoming more about hope and opportunity, and less about the more traditional doom and gloom" (Painter, 2015).

\section{Method}

\section{Stage 1: Automatic Semantic Analysis and identification of key domains}

With a view to understanding how 'uncertainty' is discussed in relation and proximity to climate change at two points in time, we extracted two corpora from Nexis ${ }^{\circledR}$ using the search terms 'climate change' OR 'global warming' AND 'uncertainty' and generated a 2010 corpus and a 2014/2015 corpus. We searched 'UK national newspapers' overall, which comprise the full-text national newspapers distributed throughout the UK from across the political spectrum (The Times, The 
Guardian, The Daily Telegraph, The Independent, The Daily Mail, The Mirror, The Sun, The Express, The Daily Star, The Observer, The People, Morning Star, The Business) including their online counterparts. This enabled us to consider not only depictions of different aspects of climate change as uncertain, but also texts where climate change might be discussed alongside other events or principles that are debated in relation to 'uncertainty'.

The 2010 corpus initially comprised 351 articles. It became clear however, that many of the articles were duplicate publications: for example, both a print and online version. Clear instances of duplication were removed; however, if an article appeared in a weekday edition of a publication but was developed into a more substantial piece for say, a weekend edition then both were retained. The non-duplicate 2010 corpus comprised 298 articles (304 188 words). The second corpus, which contains articles collected between $1^{\text {st }}$ August 2014 and 31 st July 2015, contained 408 articles. The non-duplicate 2014/2015 corpus comprised 302 articles (444 565 words). In order to consider how the headlines operated to shape the meaning of uncertainty, we generated a sub-corpus of the 298 article titles from 2010 and the 302 articles from 2014/2015, containing 4664 words and 8339 words respectively. Despite comprising a comparable number of articles the $2014 / 15$ contains a lot more words; this may reflect a trend for a more substantial headline-byline format in online articles but is not a feature that is explored here.

The 2010 corpus; $2014 / 2015$ corpus; 2010 Headlines sub-corpus and 2014/2015 Headlines sub-corpus were analysed using the corpus analysis tool WMatrix. This software, developed at the Lancaster University Centre for Corpus Research on Language (Rayson, 2003), enables corpus annotation and extends the keyword method to grammatical and semantic word domains. Keyword analysis identifies particular lexical items that appear significantly more (or less) frequently in comparison with a reference corpus and thereby reveals the 'aboutness' of a text (Scott, 1997). The WMatrix tool offers the same analysis of keyness of words that are grouped by semantic category. In this way, the tool is inclusive of a wider field of lexical items that are used to denote for example 'uncertainty', such as 'doubt', 'unclear', 'contentious', 'unsure' etc., as well as all morphological forms of the word 'uncertainty' itself ('uncertain', 'uncertainty', 'uncertainties').

The WMatrix tool relies on a pre-determined semantic categorisation system (USAS) that consists of an initial grammatical (or Part-of-Speech: POS) tagging to attach a set of potential semantic tags to each lexical unit (accounting for single words and multi-word expressions such as 'at 
the end of the day') before a process of 'disambiguation'. In order to select the contextually appropriate semantic tag the software takes the POS-tagging information (which will distinguish for example, nouns from verb forms of a word like 'spring'), considers general likelihood based on frequency in English more broadly, and the domain of discourse as determined by the wider text (e.g. a political piece would prompt a reading of 'party' as an organisation rather than a social event) (Rayson, 2003). The POS-tagging feature has a reported accuracy of $97 \%$ and the semantic tagger 92\% (Rayson, 2003) however it has been shown to perform higher when analysing both spoken and written datasets of general English (99.39\% and 97.59\% respectively) (Piao et al., 2004). Piao et al. (2004) found the USAS tagger to have $95.38 \%$ lexical coverage of a narrow domain corpus comprising journalistic reports from the UK Press Association on law/court stories from the METER corpus and the tool has been used in the analysis of metaphor (Hardie et al., 2007), literary linguistics (Archer \& Culpeper, 2009; Mclntyre \& Archer, 2010), as well as historical and non-standard forms of English (Archer et al., 2003; Xiao 2009; Piao et al., 2015). Therefore, despite being developed for the automatic semantic analysis of more general types of English, it seemed that the USAS tagging software would nevertheless be able to accurately account for the more specific discourse domain under investigation here, with manual checking of those lexical units that the software template failed to identify (which would be allocated in its 'Unmatched' category).

Using the semantic categorisation feature, we compared which themes were most prominently discussed in relation to climate change and 'uncertainty' in 2010 and in 2014/2015. The prominence of particular semantic categories is indicated by a statistical measure of log-likelihood, which determines the degree to which each word category occurs more frequently than in 'ordinary' language data. As a representation of 'ordinary' language data the WMatrix program has built within it the British National Corpus (BNC), which comprises 100 million words of spoken and written data collected from a number of different formal and informal contexts. More specifically, the BNC Written Sampler, which comprises 1 million words of written data, was used in comparison to our target data so as not to conflate the data with comparison to features of spoken discourse.

\section{Stage 2: Manual identification of the subject(s) of 'uncertainty' discourse}

The semantic annotation tool and key domain comparison allowed us to demonstrate which themes were most commonly associated with discussions of climate change and uncertainty in press 
coverage. A closer examination of the occurrence of these words in context revealed the words that help to shape how climate change is perceived by readers.

The data were defined by the search terms 'climate change' OR 'global warming' AND 'uncertainty', which did not mean that 'uncertainty' was necessarily discussed in relation to climate change. Rather, the data captured discussions of climate change in newspaper articles where the term 'uncertainty' was used, often in relation to other topics. Expanding the lexicon of 'uncertainty' to include all of the terms that were incorporated into the WMatrix semantic word category 'Unlikely' (uncertainty, doubt, unlikely, impossible, contentious, tentative, inconclusive, disputed, unsure, wavering, improbable, hesitant, think_twice, ambivalent, unclear, dubious, indeterminate etc.) we documented what it was that was being described as 'uncertain'.

Each occurrence of the terms was tallied under the following categories for both the 2010 and 2014/2015 corpora:

- Existential: where 'uncertainty' itself was the subject ("Uncertainty is a part of everyday life") or the subject was a symbolic use of the deictic 'there' ("There is considerable uncertainty").

- Climate Change broadly, with further sub-categories for Climate Science, Climate change mitigation and Communicating climate change. For the 2010 corpus a separate subcategory Anthropogenic Global Warming (AGW) was generated, as it was a referent that was frequently mentioned specifically. Similarly, for the $2014 / 2015$ corpus mentions of Fracking were tallied under a distinct sub-category. There were no mentions of 'fracking' in the 2010 corpus.

- Energy: where the subject represented any form of power supply, investment or development of renewable energy, for example.

- Mentions of 'uncertainty' in relation to elections, government or policy for example, were tallied under a Politics category.

- Economy: where the subject was the (global) economy including the recession, investment, or market prices.

- Science \& technology: where the subject was science that was not specifically climate science, including statistical modelling and the impact of technology.

We also documented the occurrence of words in the 'Danger' semantic category in each text, as well as the subject to which they referred, using the same categories as with the 'Unlikely' lexicon 
(Existential; Climate Change [including its sub-categories]; Energy; Economy; Science \& technology). This category comprised the words risk, risks, at_risk, dangerous, dangers, endangered etc. and in Stage 1 of the analysis we observed an increase in the occurrences of these terms between 2010 and 2014/2015. This increase is consistent with (and influenced by reports on) the concern of commentators in the field that discussions of climate change move away from an 'uncertainty' discourse towards a 'risk' discourse (Painter, 2013).

\section{Findings}

\section{Stage 1: A Semantic Overview of the 'Climate Change-Uncertainty' Corpora}

Below are the top 20 semantic categories from both the 2010 and 2014/2015 'Climate ChangeUncertainty' corpora (See Table 1). The categories are arranged in descending order of Loglikelihood, which is the statistical value by which they appear more frequently than 'normal' (compared with the reference corpus, the BNC Written Sampler). The categories at the top of the table represent the semantic grouping of words that appear with the greatest 'unexpected' frequency when compared with ordinary language use.

The core themes of climate change discourse remain largely consistent between 2010 and 2014/2015, with 15 of the top 20 categories in each corpora being the same, including the word category 'Unlikely'. Although higher in the 2010 corpus ranking, the number of occurrences of words in this category is similar: 718 occurrences in the 2010 corpus compared with 708 in the 2014/2015 corpus. The word category 'Evaluation: True' however, is shown to be far more prominent in the 2010 corpus compared with the $2014 / 2015$ corpus. This category includes the words: evidence, fact, truth, credibility and honest and reflects a stronger preoccupation with the contested views of anthropogenic climate change following Climategate. Another indicator of this focus is the prevalence of the category 'Knowledge'; this category comprises 221 occurrences of the word 'data', which was frequently discussed in relation to 'manipulating data', 'releasing data' and 'source/raw data', referring specifically to the data of the Climatic Research Unit. In the headlines of the 2010 corpus (see Table 2) the word categories 'Violent/Angry' (threat, turmoil, fury, anger, threatens, furious, outrage etc); 'No Constraint' (leaked, freedom, broken_out, chaos etc.); 'Evaluation: Inaccurate' (wrong, mistakes, inaccurate, error, blunder etc.); and even 'Telecommunications' (e-mail) are prevalent, further 
supporting this observation that the Climategate affair constituted the 'headline' of the climate change debate at this point and was reported through highly (negatively) evaluative language.

The word categories 'Weather', 'Green Issues' and 'The universe' reflect a topical focus around climate change through terms such as climate, weather, flooding; environmental, pollution, energy_policy; and world, planet, atmospheric respectively. Similarly, the word categories 'Substances and materials: Gas' (which comprises the words gas, co2, carbon_dioxide etc.) and 'Interested/excited/energetic' (largely made up of reference to energy: 579 instances ( $54.8 \%$ of the category) in the 2010 corpus and 880 instances (60.2\%) in the 2014/5 corpus) reflect a focus on aspects of climate change, though we may consider whether such a categorisation system should distinguish between 'energy' as a source of power and all other uses of the term. The WMatrix tool, despite identifying a number of multi-word expressions (such as university_of_East_Anglia) does not as yet identify 'climate change' as a compound and as such, the number of occurrences of 'climate' in the word category 'Weather' is matched with an equal number of occurrences of 'change', which can account for the prominence of the semantic category 'Change' in both corpora.

Given that climate change remains a highly politicised issue, it is unsurprising that the word categories 'Government' and 'Politics' are prevalent in both corpora. Although both corpora include coverage of a UK General Election, the 2014/2015 corpus incorporates a longer period leading up to the General Election, which may account for the elevated prominence of these word categories. With climate science and technological responses to climate change being highly contested issues one can expect to find 'Science and technology' to be prevalent in both corpora. The word category 'Work and Employment: Professionalism' reflects issues of scientific authority, credibility and consensus, made up of words such as secretary, colleagues, reputation etc. These issues remain important topics in the discussion of climate change.

The word category 'Other proper names' captures the variety of agents involved in the discussion by way of proper nouns: the_royal_society, UN, BBC, EU, university_of_East_Anglia, democrats etc. It is the nature of journalism that authors report the claims, findings, involvement etc. of other agents in their discussion and it is worth mentioning that both the University of East Anglia and the Royal Society were attacked during and after Climategate. As such, it would be interesting to conduct an examination of the 'credibility' of particular agents and who operates as an authoritative voice in climate change discourse, but this is not explored here. 
The semantic tagger was unable to identify 10047 of 2188085 lexical units $(3.49 \%)$ in the 2010 corpus and 12535 of 416951 lexical units (3.00\%) in the 2014/5 corpus, which constituted the 'Unmatched' categories. The words in this category tended to be specific proper nouns relating to the topic, such as 'IPCC', 'Climategate', 'Beddington', 'Merkel' etc. and so were manually reallocated to the 'Proper nouns'/'Personal names' categories. The word categories that would be included in the top 20 lists following the removal of an 'Unmatched' category would be 'Geographical terms' (global, earth, atmosphere, glaciers) for the 2010 corpus and 'Money: cost and price' (price, cost, bill, worth, tariff) for the $2014 / 2015$ corpus. The former remains consistent with a 'climate change' focus but the latter indicates more of a concern with the economic aspects of climate change, in particular the associated costs of climate change mitigation and energy policy. This is consistent with the prevalence of the word category 'Money and pay' in the $2014 / 2015$ corpus, which incorporates the terms tax, subsidies and investments.

In the 2010 corpus there are two prevalent categories concerned with 'Temperature'. In the category 'Temperature' we find the terms temperature, thermal, melted etc. and the category 'Temperature: Hot/on fire' comprises the words warming, heat, melting etc. Both categories appear in the top 30 semantic categories for the $2014 / 2015$ data. This suggests a consistent discussion of climate change in relation to (rising) temperatures, with perhaps more of a focus on and use of the term 'global warming' in the 2010 data.

In the $2014 / 2015$ corpus we observed an increased prominence of the word category 'Danger' compared with the 2010 corpus, which contains the words: risk, risks, at_risk, dangerous, dangers, endangered etc. In the 2010 corpus there are 324 occurrences of words in this category, making it the $26^{\text {th }}$ most prevalent semantic category. In the 2014/2015 corpus, there are 627 occurrences of words in this category. Of course this particular corpus does not take into account articles that refer to 'climate change' (and potentially 'risk') that do not refer to 'uncertainty' in some way. Nevertheless, this approach has still captured a quantifiable increase of 'risk' (here 'Danger') vocabulary in relation to climate change between 2010 and 2014/2015.

\section{Headlines}

The top 20 semantic categories from both the 2010 and 2014/2015 'Climate Change-Uncertainty: Headlines' sub-corpora are presented in Table 2. Twelve of these top 20 categories appear in both 
corpora and many of the categories are consistent with the larger corpora, notably: 'Weather';

'Geographical terms'; ‘Green issues'; 'Science \& technology in general’; 'Substances \& Materials:

Gas'; 'Change'; 'Politics'; ‘Government'; 'Other proper names'; ‘Speech acts'; 'Speech:

Communicative'; and 'Degree'.

The word category 'Unlikely' appears as the $21^{\text {st }}$ and $28^{\text {th }}$ most prevalent category in the 2010 and 2014/2015 Headline sub-corpora respectively. This reflects 11 instances of words in the category 'Unlikely' in the 2010 Headlines sub-corpus (298 articles) and 17 instances in the 2014/2015 Headlines sub-corpus (302 articles). This suggests that the question of 'uncertainty' is less often the topic of the discussion itself and more often an attached determiner of the topic (be it climate change, the economy, an election etc.). This observation prompted the second stage of our analysis in which we examined the referents of 'uncertainty' in the data and is explored below.

In the 2010 Headlines sub-corpus, which, as shown above, was dominated by the Climategate affair, journalists appeared to distance themselves from the claims of 'experts' through reported speech such as "say experts" [2010, \#110]; "warn volcano experts" [2010, \#159]; "Expert warns of electricity grid crisis" [2010, \#237]; and more explicitly by characterising them as an "outgroup', "We ask a range of experts" [2010 \#56] who are called into question: "Most experts are no better at telling the future than a dustman. So why do we prize their simple certainties?" [2010, \#305]. This reference to 'experts' accounts to some degree (8 instances of 28 tokens, $28.6 \%$ ) for the prevalence of the word category 'Knowledgeable', which comprises the words experts, warns, news, climatologist etc.

The prevalence of the word category 'Interested/excited/energetic' in the 2014/2015 Headlines corpus reflects a more prominent discussion of 'energy' in terms of 'supply', 'investment' and 'systems'. Similarly, the word category 'Substances \& Materials: Liquid' reflects a focus on both 'water' and 'oil' supplies. As suggested above, this is indicative of international tensions within Europe, with respect to trade and the economy but also to alternative energy policies.

The prevalence of the word category 'The universe' in the 2014/2015 Headlines corpus reflects a more global characterisation of climate change, referencing 'the world's climate', 'the world's electricity' and 'the World Energy Council'. Conversely, the prevalence of the word category 'Geographical names' foregrounds climate change at a national level, comprising the words 'UK'/ 'Britain' and 'Australia'. This is a consequence of a shift towards the implications and responses to 
climate change, which operate at a national and global level, as opposed to the discussion of the reality of climate change.

The word category 'Hindering' offers some indication of how discussions of climate change have potentially moved away from characterisations of 'uncertainty' through references to 'combat[ting] climate change' [2014/2015, \#47]; 'help fight climate change' [2014/2015, \#355]; and 'prevent[ing] climate disaster' [2014/2015, \#127], where the issue of 'climate change' is discussed as a given phenomenon. In fact, in the following headline from the $2014 / 2015$ corpus we find that it is the 'undermin[ing]' of climate science that is 'debunked': “Global warming 'pause' didn't happen, study finds; Reassessment of historical data and methodology by US research body debunks 'hiatus' hypothesis used by sceptics to undermine climate science" [2014/2015, \#365]. What is undetermined at this stage is not the existence of climate change itself but rather the mitigation of it, as shown through this word category 'Hindering', which highlights the headline content: 'Subsidy blow to proposed wind farms' [2014/2015, \#371] and those who 'oppose a second [drilling] site' [2014/2015, \#372].

\section{Summary of Stage 1 Findings}

Stage 1 of the analysis has shown that the most prevalent themes in climate change discourse remain consistent between 2010 and 2014/2015. In the 2010 data there is more discussion of the turmoil of leaked e-mails and subsequent mistrust of experts instigated by Climategate. In the $2014 / 2015$ corpus we find more of an emphasis on climate change mitigation where 'uncertainty' is used in reference to energy policy and the unknown impacts of action on climate change, as well as word categories capturing terms to do with 'money' and 'cost'. In the Headlines for 2014/2015 there is more emphasis on action on climate change, at a national and global level. In the 2014/2015 corpus the word category 'Danger' was more prevalent, indicating a greater use of 'risk' discourse. In Stage 2 of the analysis, we examine how discourses of 'uncertainty' and 'risk' operate in relation to the key themes of our data, including specific aspects of climate change.

\section{Stage 2: The nature of climate change uncertainty and other 'uncertainty' discourses 'Uncertainty' and 'Risk' discourses}

Figure 1 shows the number of occurrences of words in both the 'Unlikely' (i.e. uncertainty) and 'Danger' (i.e. risk) lexicons in relation to the topics Existential; Climate Change; Energy; Politics; 
Economy; Science \& Technology; and Other. There is a decrease in mentions of 'uncertainty' in relation to Climate Change, Science \& Technology and as an Existential category between the 2010 and 2014/2015 corpora. In both corpora we find mentions of the "uncertainties of climate change" [2010, \#40], "uncertainty and doubt on the reality of climate change" [2014/2015, \#6], however in the $2014 / 2015$ corpus there is more often an emphasis not on the disputed reality of climate change itself but rather "uncertainty over the precise extent of warming" [2014/2015, \#157]. There are only two mentions (within one article) of 'Climategate' in the 2014/2015 corpus, which appears as something of a footnote to a discussion about climate scientists communicating uncertainties.

[Fig.1 Occurrences of words in the 'Unlikely' and 'Danger' categories in relation to topic]

In the 2010 corpus 126 of the 298 articles mention 'uncertainty' but do not do so in relation to climate change. In the $2014 / 2015$ corpus 159 of the 302 articles mention 'uncertainty' but not in relation to climate change. There is a slight increase in occurrences of terms in the 'Unlikely' lexicon between 2010 and 2014/2015 in relation to Energy (37 to 43 occurrences); Economy (36 to 41); with a negligible decrease in occurrences relating to Science \& Technology (13 to 12) (see Fig. 1). We see the greatest increase (from 61 in 2010 to 80 in 2014/2015) in relation to Politics, though this may reflect a more extended coverage of the lead-up to the UK General Election in the 2014/2015 corpus. An increase in 'Danger' terms in relation to Energy, Politics and the Economy shows that, overall, there is greater emphasis on these topics more broadly alongside mentions of 'climate change' and 'uncertainty' in the $2014 / 2015$ corpus.

In the UK context, the sacking of the environment secretary Owen Patterson in July 2014 prompted a number of discussions about the UK's Climate Change Act of 2008, with Patterson himself claiming the predicted effects of climate change had been "consistently and widely exaggerated" [2014/2015, \#65]. Such discussions however focused on the political-economical aspects, considering the 'uncertain' implications of national energy policy for British businesses. Thus while Patterson himself called into question the 'certainty' of climate change, commentators in the media did not take up this discussion in 'uncertain' terms but rather wrote about the 'uncertainty' attached to a change in policy and subsequently, the economy. 
In the 2010 corpus "political and regulatory uncertainty" [2010,\#58] is discussed in relation to investment in UK businesses, putting the issue of climate change at the periphery of the discussion. Perhaps more localised to climate change issues are discussions about the 'uncertainty' of (subsidies for) renewable energy projects, such as electric cars [2010, \#243]. However in either case, it is not 'climate change' that is characterised as 'uncertain'. In the $2014 / 2015$ corpus the uncertainties of an upcoming General Election and subsequently the UK Economy and Energy Policy are very much intertwined so discussion for example of Contracts for Difference for renewable energy are characterised by political uncertainty - once again placing climate change on the periphery of the discussion.

Figure 1 shows an increase in the use of 'Danger' terms in relation to climate change and Figure 2, which shows the breakdown of these occurrences in relation to the different aspects of climate change, shows that this increase is ultimately in relation to climate change as a broad phenomenon. There is an increase of 'Danger' terms in relation to 'climate change' from 51 occurrences in the 2010 data to 92 occurrences in $2014 / 2015$, including a rise in mentions of 'climate change risks'/'the risks of climate change' (from one occurrence in the 2010 corpus to 22 occurrences in the $2014 / 2015$ corpus). In the 2010 corpus there are six occurrences of the phrase 'dangerous climate change' [2010, \#52; \#70; \#292; \#308; \#326] compared with 43 depictions of climate change as 'dangerous' in the $2014 / 2015$ corpus.

\section{Dimensions of Climate Change}

In the 2010 corpus 172 of 298 articles used at least one 'Unlikely' term (uncertainty, doubt, unlikely, impossible, etc.) in relation to some aspect of climate change. In the 2014/2015 corpus 143 of 302 articles used an 'Unlikely' term in relation to some aspect of climate change. Figure 2 shows the number of occurrences of terms in the 'Unlikely' and 'Danger' lexicons in relation to the subcategories of the 'Climate Change' category, including broad references to climate change as a phenomenon; climate science; communicating messages about climate change; climate change mitigation (including for example, geoengineering); and separately, AGW for the 2010 corpus and Fracking for the $2014 / 2015$ corpus.

In the $2014 / 2015$ corpus the occurrences that make up the more broad 'Climate change' category come from articles that are not 'about' climate change and so do not go into specific detail 
about the phenomenon. For example, an article about the implications of Scottish independence for small businesses uses "the challenges we face from climate change" as an example of how "we live in an increasingly uncertain world" [2014/2015, \#33]. This is in sharp contrast to the 2010 corpus in which occurrences of this type are broadly found in articles 'about' climate change, such as one with the headline "Sharp decline in public's belief in climate threat, British poll reveals" [2010, \#96]. Thus while there appears to be an increase in the characterisations of 'climate change' as 'uncertain', using the figures from the larger categories (as shown in Fig. 1) we can say that it is only in cases where climate change is not discussed through a more specific dimension (such as climate science or mitigation). This has implications for readers who may read about climate change as a peripheral topic and not engage with those discussions (articles) in which it is discussed in more depth. For those readers, there is a sense that climate change continues to be characterised in 'uncertain' terms.

\section{Climate science}

There were 174 occurrences of 'Unlikely' terms in relation to climate science in the 2010 corpus compared with 63 in the 2014/2015 corpus (see Fig. 2). In the 2010 corpus we find statements such as "There is a fundamental uncertainty about climate change prediction that can't be changed" [2010, \#24]. In comparison, we find consideration of the extent to which climate science offers reliable knowledge in the 2014/2015 corpus: "Other things being equal, carbon dioxide emissions will produce some warming. The question always has been: how much? On that there is considerable uncertainty" [2014/2015, \#65]. In addition to there being fewer mentions of 'uncertainty' in relation to climate science in the $2014 / 2015$ corpus these are distributed across fewer articles (97 different articles in the 2010 corpus to 47 articles in 2014/2015). This indicates that discussions in 2014/2015 less frequently characterised climate science (prediction) as 'uncertain' and also suggests that this was less often a prominent theme in the article. With fewer mentions in relation to 'Danger' as well, it would seem that climate science was altogether an aspect of climate change that received less attention in 2014/2015, with the scientific basis of climate change largely uncontested and the extent of climate change becoming more of a focus.

[Fig.2 Occurrences of words in the 'Unlikely' and 'Danger' categories in relation to aspects of climate change] 


\section{Communicating climate change}

Figure 2 shows a general decrease in references to communicating climate change, in relation to both 'Unlikely' and 'Danger' terms. This category is characterised by statements that encourage the frank and open discussion of the 'uncertainties' of climate change, such as ensuring that these are acknowledged in publications or bringing to attention when commentators had "failed to reflect uncertainties" [2010, \#153]. In the 2010 corpus we find examples of articles in which this is very much the main topic, such as the article entitled "Scientists need the guts to say: I don't know; From climate change to swine flu, we must rebuild trust by being honest about risk" [2010,\#125], which also introduces a 'risk' discourse. This embracing of more honesty and openness about scientific uncertainties can be seen as a positive outcome of the Climategate affair.

Similar articles can also be found in the $2014 / 2015$ corpus, such as an article entitled "Climate change scientists urged to be more open to the public about uncertainties; A new report calls for experts to communicate their research more clearly" [2014/2015, \#366], and Adam Corner's "12 tools for communicating climate change more effectively" [2014/2015, \#386]. This indicates that there are still concerns about the transparent communication of 'uncertain' aspects of climate change, though in the latter example it is specifically recommended that commentators discuss climate change more in terms of 'risk' rather than 'uncertainty'.

It is worth noting that of 23 occurrences of 'unlikely' terms in relation to 'communicating climate change' in the $2014 / 2015$ corpus, 15 occur within these two articles. Similarly, the 5 occurrences of 'Danger' terms appear in 3 articles (compared with 16 occurrences across 16 articles in the 2010 corpus). Occurrences in this category largely relate to the rhetoric of climate change discussion, such as the concern that "the media furore is skewing the debate on climate change" [2010, \#79] and in 2014/2015, "A common strategy of sceptics is to intentionally confuse and conflate different types of uncertainty" [2014/2015, \#386]. The distribution of these instances would suggest that in the 2014/2015 corpus occurrences of both 'Unlikely' and 'Danger' terms appear when the communication of climate change issues is a more prominent topic of discussion, whereas instances in the 2010 appear more incidental to a broader topic. What is also in evidence in the $2014 / 2015$ corpus are articles that discuss "manufactured doubt" [2014/2015, \#265], comparing the 'uncertainty' discourse around climate change to that of the tobacco industry and characterising it as an industrial 
'agenda'. This suggests that the acceptance of climate change is the prevailing idea that is actively being undermined.

\section{Climate change mitigation}

As a form of climate change mitigation, there are a number of references to 'Fracking' in the 2014/5 corpus (20 'Unlikely'; 15 'Danger'). There are no mentions of Fracking in the 2010 corpus, which does discuss the uncertainties of biochar [2010, \#252] and the 'dangers' associated with offering tariffs on wind-power supplies [2010, \#141]. A Commons debate in January 2015 on fracking in the UK prompted a number of articles in the $2014 / 2015$ corpus that highlighted the 'health risks' and 'uncertainties' about the impacts of the extraction of shale gas.

\section{AGW}

In the 2010 corpus Anthropogenic Global Warming/AGW/Anthropogenic climate change is described as a 'hoax' [2010, \#45], a 'scam' [2010, \#128; \#224], a 'scare' [2010,\#225], the 'cause' of 'alarmists' [2010, \#224] and the product of journalistic bias [2010, \#251]. One article [2010, \#160] did quote Bill McGuire, head of the Benfield Hazard Research Centre at University College London, referring to the "increased risk" associated with global temperature rise whereby anthropogenic global warming is cited without mitigation or qualification. In the 2014/2015 corpus there is but a single mention of Anthropogenic Global Warming/AGW, which states that "The basic concept of anthropogenic climate change is now generally accepted worldwide" [2014/2015, \#336].

\section{Summary of Stage 2 Findings}

The observed 'uncertainty' discourses between 2010 and 2014/2015 show a change from using uncertainty to question climate science and the authority and credibility of climate scientists to discussing the uncertainties inherent in various climate change mitigation activities: uncertainties that go beyond science and reach into the economy, environment and politics more generally. Both the scientific basis of climate change and the principle of AGW are characterised in fewer and less 'uncertain' terms in the 2014/2015 corpus. There are altogether fewer articles 'about' climate science and the characterisation of climate change more broadly as 'uncertain' seems to occur largely in articles that are not 'about' climate change in any real detail. Furthermore, in the 2014/2015 corpus 
climate change is discussed alongside other 'uncertain' topics, largely the political and economic landscapes of the UK without itself being referred to in 'Unlikely' terms, suggesting that while the results of the UK General Election and subsequently energy policy may be 'uncertain', the reality of 'climate change' is not. There is an increase in 'risk' terms used in relation to climate change, which is characterised as 'dangerous' and complements this change in focus to the effects of climate change and a consideration of responses to it.

\section{Discussion}

This study demonstrates how a corpus-assisted approach to examining climate change discourse allows us look at the discussion of uncertainty in the context of climate change at two different periods in time and to show how differences in politics, culture and economics shape the way the 'uncertainty' is discussed or used. It also shows what impact 'uncertainty communication' itself may have on climate change debates.

This approach relies on the use of particular lexical items and although the semantic categorisation feature of the WMatrix software has shown to be highly comprehensive, it is by no means exhaustive. We have used its categories of 'Unlikely' and 'Danger' as proxy for discourses of 'uncertainty' and 'risk' respectively and shown in what way the discussions of 'uncertainty' in relation to climate change differed in the mainstream journalism of the UK in 2010 compared to 2014/2015. While in 2010 (research question 1) there was a preoccupation with the reliability of climate science and the credibility of climate scientists, arguably instigated by Climategate, in 2014/2015 (research question 2) there was more concern for the effects of and responses to climate change at a national and global level. These are the issues that the Paris climate deal at the end of 2015 has been constructed to address.

Semantic categorisation has demonstrated that climate change remains an important political, economic and scientific issue and that equally, it is implicated in discussions of change brought about by general elections and the global economy. Nevertheless, the emphasis on action on climate change has facilitated a discussion of the risks of climate change and the contingencies in response to political/economic uncertainties, which is in keeping with the recommendations of climate change commentators such as Corner et al. (2015). Thus, while there remain discussions about the 'uncertainty' of the extent of climate change and the value of fracking for example, what is less 
uncertain is the reality of climate change and its scientific basis. This has implications for climate change communication (research question 3 ), as this new way of discussing uncertainty might provide climate change communicators with a more solid platform on which to operate.

\section{Author's Declaration}

The Authors declare that the manuscript has not been published elsewhere or in another language, and has not been and will not be submitted to other journals simultaneously. Brigitte Nerlich acknowledges the support of the Leverhulme Trust through the Making Science Public programme (RP2011-SP-013).

\section{References}

Archer, D. McEnery, T., Rayson, P., \& Hardie, A. (2003). Developing an automated semantic analysis system for Early Modern English. In D. Archer, P. Rayson, A. Wilson \& T. McEnery (Eds.), Proceedings of the Corpus Linguistics 2003 conference. UCREL technical paper number 16. (pp. 22-31). UCREL, Lancaster University. Retrieved from: http://comp.eprints.lancs.ac.uk/763/1/cl2003 archerEtAl.pdf, accessed 29 February 2016.

Archer, D. \& Culpeper, J. (2009). Love - "a familiar or a devil"? An exploration of key domains in Shakespeare's comedies and tragedies. In D. Archer (ed.) What's in a Word-List? Investigating Word Frequency and Keyword Extraction. (pp. 136-57). London: Ashgate.

Carvalho, A. \& Burgess, J. (2005). Cultural Circuits of Climate Change in U.K. Broadsheet Newspapers, 1985-2003. Risk Analysis, 25(6), 1457-68.

Corner, A. (2014). The Uncertain World: Is uncertainty used as a stick with which to beat climate change? Blog post, Cabot Institute, Bristol. Retrieved from: http://cabotinstitute.blogspot.co.uk/2015/10/the-uncertain-world-can-uncertainty-be.html, accessed 1 January 2016.

Corner, A., Lewandowsky, S., Phillips, M., \& Roberts, O. (2015). The Uncertainty Handbook. Bristol: University of Bristol.

Fairclough, N. (2003). Analysing Discourse: Textual Analysis for Social Research. London: Routledge.

Firestein, S. (2015). Scientific method: Tales of the unexpected. Nature, 526, 638-9.

Hardie, A., Koller, V., Semino, E., \& Rayson, P. (2007). Exploiting a semantic annotation tool for metaphor analysis. In M. Davies, P. Rayson, S. Hunston \& P. Danielsson (Eds.) Proceedings of the Corpus Linguistics 2007 Conference. Retrieved from:

http://www.birmingham.ac.uk/documents/college-artslaw/corpus/conferencearchives/2007/49Paper.pdf, accessed 29 February 2016.

Jaspal, R. \& Nerlich, B. (2014). When climate science became climate politics: British media representations of climate change in 1988. Public Understanding of Science, 23(2),122-41.

Koteyko, N., Jaspal, R., \& Nerlich, B. (2013). Climate change and 'climategate' in online reader comments: A mixed methods study. The Geographical Journal, 179(1), 74-86.

Landström, L., Hauxwell-Baldwin, R., Lorenzoni, I., \& Rogers-Hayden, T. (2015). The (Mis)understanding of Scientific Uncertainty? How Experts View Policy-Makers, the Media and Publics. Science as Culture, 24(3), 276-98. doi: 10.1080/09505431.2014.992333

Lewandowsky, S., Ballard, T., \& Pancost, R. D. (Eds.) (2016). Responding and adapting to climate change: Uncertainty as knowledge. The Royal Society. Retrieved from: http://rsta.royalsocietypublishing.org/content/responding-and-adapting-climate-changeuncertainty-knowledge, accessed 1 January 2016

Mclntyre, D. \& Archer, D. (2010). A corpus-based approach to mind style. Journal of Literary Semantics, 39(2), 167-82.

Nerlich, B. (2010). 'Climategate': paradoxical metaphors and political paralysis. Environmental Values, 19(4), 419-42. 
Nerlich, B. (2012). Languages of uncertainty. Making Science Public. Retrieved from: https://blogs.nottingham.ac.uk/makingsciencepublic/2012/04/04/languages-of-uncertainty/, accessed 1 January 2016.

Nerlich, B. \& Jaspal, R. (2012). Metaphors we die by? Geoengineering, metaphors and the argument for catastrophe. Metaphor and Symbol, 27(2), 131-47.

Nowotny, H. (2015). The Cunning of Uncertainty. London: Polity Press.

Painter, J. (2013). Climate Change in the Media: Reporting Risk and Uncertainty. Reuters Institute for the Study of Journalism, University of Oxford: I.B. Taurus.

Painter, J. (2015). Reflections from Paris. Media Watch. Retrieved from: http://www.climatematters.hamburg/2015/12/reflections-from-paris/, accessed 1 January 2016.

Pan, Z. \& Kosicki, G. M. (1993). Framing Analysis: An Approach to News Discourse. Political Communications, 10, 55-75.

Piao, S. L., Rayson, P., Archer, D., \& McEnery, T. (2004). Evaluating Lexical Resources for a Semantic Tagger. LREC 2004 May 2004, Lisbon, Portugal.

Piao, S., Bianchi, F., Dayrell, C., D’Egidio, A., \& Rayson, P. (2015). Development of the Multilingual Semantic Annotation System. Human Language Technologies: The 2015 Annual Conference of the North American Chapter of the ACL. 31 May-5 June, Denver, Colorado. Retrieved from: http://www.aclweb.org/anthology/N15-1137, accessed 29 February 2016.

Rayson, P. (2003). Matrix: A statistical method and software tool for linguistic analysis through corpus comparison. Ph.D. thesis. Lancaster University, UK.

Scollon, R. (2000). Generic variability in news stories in Chinese and English: A contrastive discourse study of five days' newspapers. Journal of Pragmatics, 32, 761-91.

Scott, M. (1997). PC Analysis of Key Words -- and Key Key Words. System, 25(1), 1-13.

Ungerer, F. (Ed.). (2000). English media texts past and present language and textual structure. Philadelphia, PA: John Benjamins.

van Dijk, T. A. (1988). News as discourse. Hillsdale, NJ: Lawrence Erlbaum.

Xiao, R. (2009). Multidimensional analysis and the study of world Englishes. World Englishes, 28(4), 421-50.

\section{Tables and Figures}

Table 1 Top 20 semantic categories for the 2010 and 2014/2015 Climate Change-Uncertainty corpora

2010 Semantic domain

1. Numbers

2. Weather

3. Science \& technology in general

4. Unmatched

5. Change

6. Unlikely

7. Substances \& materials: Gas

8. Government

9. Green issues

10. Degree

11. Temperature: Hot/On Fire

12. Interested/excited/energetic

13. Work \& Employment: Professionalism

14. Evaluation: True

15. Speech acts
2014/2015 Semantic domain

1. Weather

2. Government

3. Politics

4. Speech: Communicative

5. Other proper names

6. Science \& technology in general

7. Time: Momentary

8. Change

9. Substances \& materials: Gas

10. Green issues

11. The universe

12. Money \& pay

13. Time: Future

14. Unmatched

15. Degree 

16. Knowledge
16. Speech acts
17. Other proper names
17. Interested/excited/energetic
18. The universe
18. Unlikely
19. Temperature
19. Work \& Employment: Professionalism
20. Politics
20. Danger
26. Danger

Table 2 Top 20 semantic categories for the 2010 and 2014/2015 Climate Change-Uncertainty Headlines corpora

\begin{tabular}{|c|c|c|c|}
\hline 2010 & Semantic domain & $2014 / 2015$ & Semantic domain \\
\hline 1. & Weather & & Weather \\
\hline 2. & Science \& technology in general & & Science \& technology in general \\
\hline 3. & Temperature: Hot/On fire & 3. & Change \\
\hline 4. & Change & 4. & The universe \\
\hline 5. & Politics & 5. & Politics \\
\hline & Light & 6. & Other proper names \\
\hline & Other proper names & 7. & Geographical terms \\
\hline & Speech acts & 8. & Temperature: Hot/on Fire \\
\hline & Unmatched & 9. & Substances \& Materials: Gas \\
\hline & Degree & 10. & Green issues \\
\hline 11. & Green issues & 11. & Light \\
\hline & Knowledge & 12. & Government \\
\hline 13. & Evaluation: Inaccurate & 13. & Danger \\
\hline 14. & Violent/Angry & 14. & Degree \\
\hline 15. & Speech: Communicative & 15. & Interested/excited/energetic \\
\hline 16. & Darkness & 16. & Speech acts \\
\hline 17. & Electricity \& electrical equipment & 17. & Substances \& materials: Liquid \\
\hline 18. & Knowledgeable & 18. & Speech: Communicative \\
\hline 19. & Government & 19. & Geographical names \\
\hline 20. & No constraint & 20. & Hindering \\
\hline
\end{tabular}

Fig.1 Occurrences of words in the 'Unlikely' and 'Danger' categories in relation to topic 


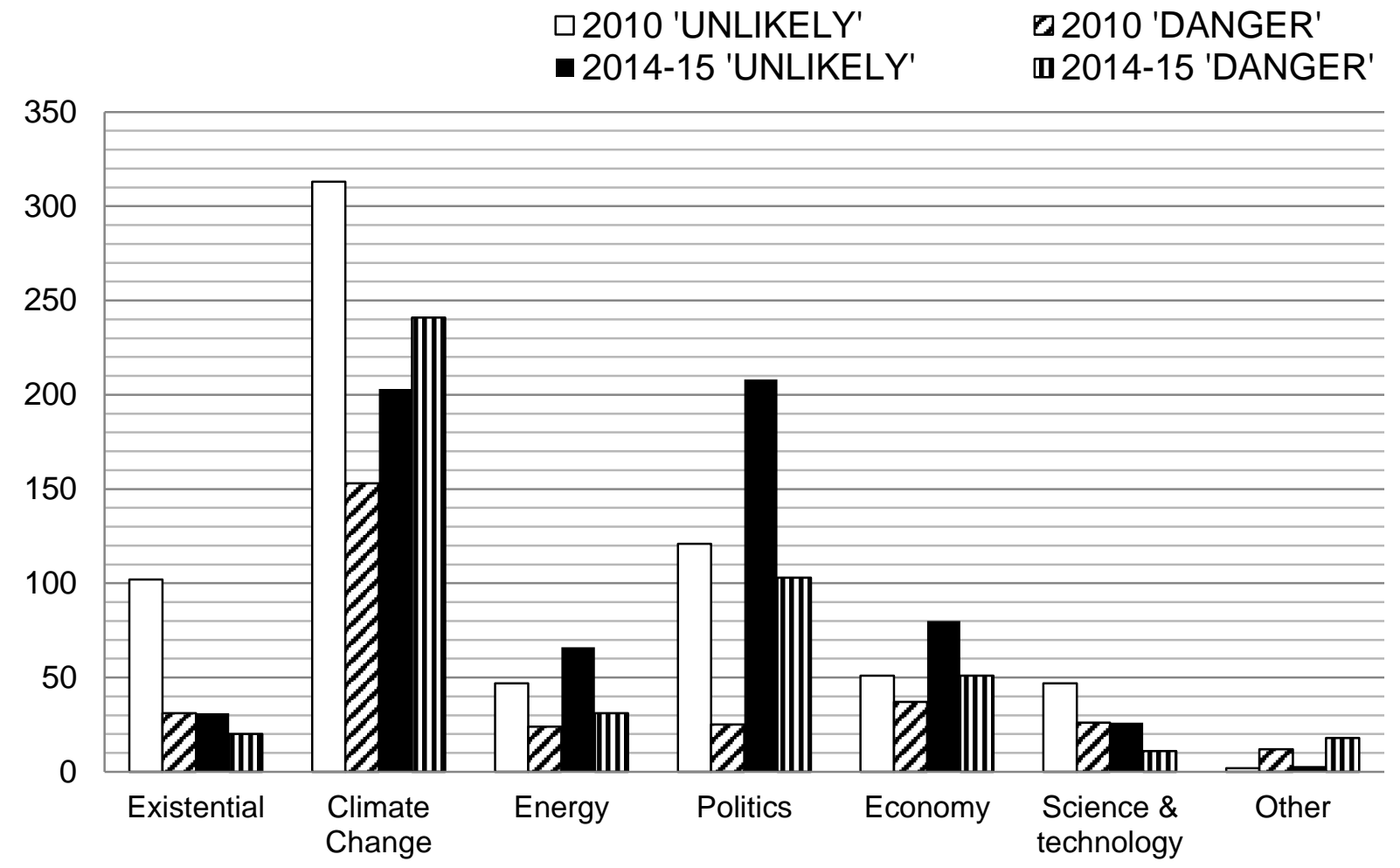

Fig.2 Occurrences of words in the 'Unlikely' and 'Danger' categories in relation to aspects of climate change

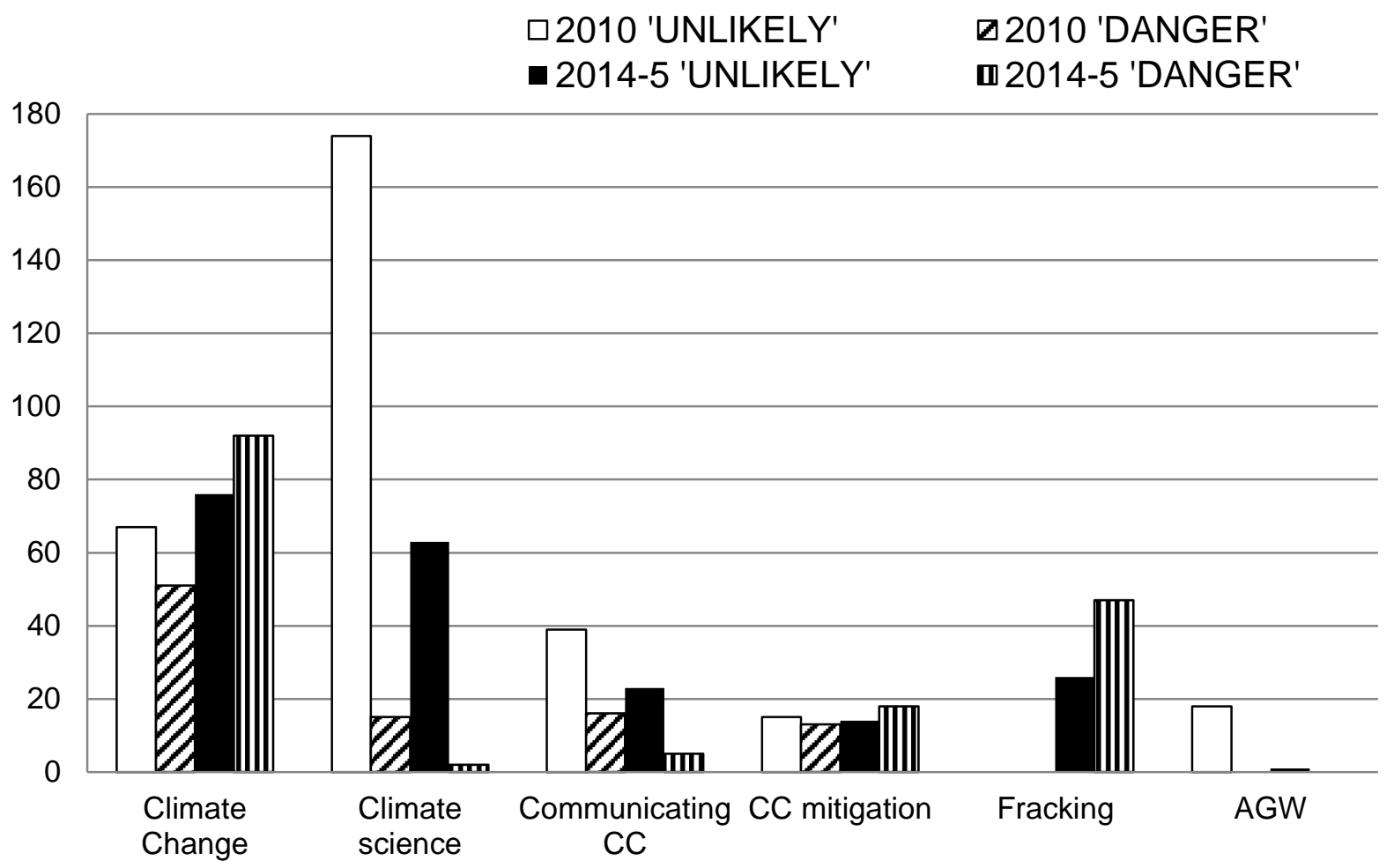

